\title{
Destitute and vulnerable: Fear of crime and victimisation among the homeless in urban and rural settings in South Africa
}

\section{Lufuno Sadiki}

Department of Social Work and Criminology

University of Pretoria, South Africa

\section{Francois Steyn}

Department of Social Work and Criminology

University of Pretoria, South Africa

\section{DOI - https://doi.org/10.35293/srsa.v43i1.367}

\section{Abstract}

In 2019, the murders of five homeless men in Pretoria drew attention to the vulnerability of people living on the street. Despite more than two decades of democracy, social injustices and inequality continue to characterise post-apartheid South Africa. In addition to rampant poverty burgeoning informal settlements and poor housing, homelessness forms an integral part of the country's urban and rural landscapes. However, homelessness is often accompanied by victimisation, racial and social injustices, and human rights violations. This paper reports on the victimisation of homeless people in South Africa, their patterns of reporting such incidences, and interactions with criminal justice agents. The paper also contextualises a fear of crime among the homeless and evaluates the limitations of the lifestyle exposure, routine activities, and deviance place theories to adequately explain injustices committed against the homeless. Implications for context-specific and global realities regarding homeless people are discussed. Quantitative data was obtained through non-probability sampling strategies from 40 urban and 30 rural homeless people. More than half of respondents felt unsafe while living on the streets (55.8\%), feared becoming a victim of crime in the next year $(54.5 \%)$ and the greater proportion of respondents $(57.1 \%)$ had fallen victim to crime in the past. Statistically significant differences $(\mathrm{p}<0.05 ; \mathrm{r}>0.4)$ featured between urban and rural respondents in terms of theft and harassment and 
anticipating victimisation. The findings highlight the social injustices suffered by homeless people, often at the hand of those who are supposed to protect vulnerable groups.

Keywords: Crime, Victimisation, Vulnerability, Homeless, Human rights

\section{Introduction}

Homelessness is a worldwide phenomenon characterised by extreme poverty, social exclusion, and a lack of access to basic services (Cross, Seager, Erasmus, Ward \& O’Donovan 2010, 6). Defining the term homelessness is a greatly contested matter, because home and homelessness take on different meanings and vary across countries. Often homelessness reflects a political orientation rather than the reality of deprivation (Tipple \& Speak 2005, 337; Makiwane, Tamasane $\&$ Schneider 2010, 39). In its policy on homelessness, the City of Tshwane Metropolitan Municipality defines the homeless as persons who find themselves on the streets with no shelter and very limited social support (Mashau 2017, 419). Pathways in and out of homelessness are neither linear nor uniform. The causes of homelessness are both structural and personal, including unemployment, migration, social exclusion, lack of access to affordable housing, poor mental health, traumatic life events, family conflict, and substance dependency (Manganyi 2017, 451; Roets, Botha, Greef, Human, Strydom, Watson \& Chigeza 2016, 622). In South Africa, homelessness is tied to the country's socio-political history of exclusion and marginalisation, as well as uncoordinated planning, ever-growing informal settlement populations, and the increase of child-headed families and associated family disintegration (Olufemi 2000, 224).

Interpretation of "homelessness" developed by local government agencies tends to minimise the homeless population and only focus on individuals who are publicly visible (Amore, Baker and Howden-Chapman 2011, 21). Therefore, homelessness is a politically sensitive subject because how it is understood determines who will be counted as homeless, and who will eventually receive financial or other support. Policies developed to address homelessness can only be effective and workable if they are based on a clear understanding of what homelessness entails (United Nations Centre for Human Settlements 2000, 447; Naidoo 2010, 131; Tosi 201, 221). Such understandings influence the extent of 
the phenomenon and it also circumscribes the possible solutions (Echenberg $\&$ Jensen 2012, 1). Solutions to homelessness require concerted efforts and collaboration between government entities and policy intervention. However, there are no comprehensive policies on homelessness in the Southern African context. Furthermore, the African Union (AU) has no policy targeted at homeless people. Available AU policies are geared towards assisting displaced persons, returnees, and refugees. In a three-day meeting held for Aspiration 3 of Agenda 2063, the member states pledged to use the spirit of ubuntu and Pan-Africanism as a strategy to end homelessness in Africa. Furthermore, the leaders reiterated the need to translate legal instruments intended to support displaced women and children into practical actions. These include having updated data on the number of displaced persons, practical medium to long-term solutions, and the monitoring of governance at host communities (AU 2020).

In African countries, displacement because of war, civil conflict, and natural disasters is a pathway to homelessness. In 2005, between May and June, operation Murambatsvina was implemented in Zimbabwe, which left thousands of Zimbabweans displaced. The operation was aimed at demolishing illegal squatters from urban areas, leaving thousands of people homeless (Dorman 2016, 84; Benyera \& Nyere 2015, 6524). The operation highlighted issues of citizenship and sovereignty in the country. The Zimbabwean government asserted that it was 'within its sovereign rights' to execute the operation (Dorman 2016, 85; Benyera $\&$ Nyere 2015, 6524). The operation had an impact on already marginalized communities, afflicting the most vulnerable members whose life chances and quality of life were already compromised by poverty (Benyera \& Nyere 2015, 6524). The operation further illustrates the importance of how housing and homelessness are defined. According to the operation, it was argued that no one was rendered homeless as the informal settlers were already homeless (Tipple $\&$ Speak 2005, 337).

Homeless persons have a greater risk of falling victim to crime compared to the general population (Kinsella 2012, 126; Garland, Richards \& Cooney 2010, 287; Larney Conroy, Mills, Burns \& Teeson 2009, 347; Rattelade, Farrell, Aubrey \& Klodawsky 2014, 1607). Violence, threats, intimidation, and abuse by the public appear to be an everyday reality for the homeless population. 'Not only are the homeless unprotected, their very identity often makes them the target of ill-treatment by members of the public' (Newburn 2006 and Rock, 
148). Understandably, homeless people experience the world as an unsafe place (Kinsella 2012, 126). Homelessness is multidimensional, it does not just refer to a lack of shelter or a lack of a roof over one's head but involves deprivation across several dimensions (Somerville 2013, 384).

Experiences of victimisation among the homeless present unique characteristics in terms of the nature of crimes committed against them, the profile of offenders, and dynamics related to the time and place of offences. In addition, homeless persons tend to underreport victimisation to the police and (Scurfield, Rees and Norman 2004, 8), by not having a fixed or registered address, they are mostly excluded from victims of crime surveys which rely on official databases for sampling purposes. Potentially due to society perceiving homelessness as (an avoidable) nuisance, homeless persons as victims of crime seldom receive media attention, and if they do reports about the crimes committed against them are sensationally framed similarly to the 2019 widespread news report assuming the serial killing of five middle-aged homeless men in Pretoria. The men were either stabbed or suffered blunt force injuries in the evening and near public areas, namely at Mears Park train station, Magnolia Park and Muckleneuk Park (Mitchley 2019).

South African research on homelessness is scarce yet some inroads into the phenomenon have been made. Studies are concentrated in urban settings, particularly in the City of Tshwane, Johannesburg, Cape Town, and Durban (de Beer and Valley 2017, 389; Kriel, Tembe \& Mashava 2017, 428; Schenck, Roman, Erasmus, Blaauw and Ryan 2017, 266; Moyo, Patel and Ross 2015,1). The focus on homelessness in urban settings has resulted in the evidence cupboard on rural homelessness being glaringly empty (Skott-Myhre, Raby and Nikolaou 2008, 88; Schiff, Schiff, Turner \& Bernard 2015, 85). Additionally, research tends to focus pertinently on homeless policies, demographic profiles and mental health, and pathways to homelessness (Naidoo 2010, 129; Du Toit 2010, 111; Kok, Cross \& Roux 2010, 21; Makiwane, Tamasane \& Schneider 2010, 39). Limited local knowledge exists regarding homeless persons' feelings of safety and the crimes committed against them hence the present paper sets out to describe the nature and extent of fear of crime and victimisation among homeless persons in urban and rural settings. The paper focuses on their feelings of safety, fear of crime, experiences of victimisation and subsequent reactions to and reporting of incidents of victimisation. 


\section{Research methods}

Survey methods were used to obtain data from 40 homeless persons living in the City of Tshwane Metropolitan Municipality (urban sample) and 30 in the Vhembe District Municipality in Limpopo (rural sample). A questionnaire was developed from existing instruments, in particular victims of crime surveys. Data was gathered through face-to-face interviews due to the anticipated low literacy levels of homeless persons (Kumar 2014, 182). For quality purposes, the questionnaire was tested with six homeless persons prior to the survey and resulted in the reformulation of a few questions.

Purposive sampling was used to identify respondents because homeless persons do not have a fixed residential address or any other type of identification from which a random sample can be drawn. Shelters and feeding programmes were used as entry points to find potential respondents. The data was electronically captured and analysed using the Statistical Package for the Social Sciences (IBM 2019). Since the data did not show a normal distribution and because a nonprobability sampling strategy was followed, non-parametric procedures, in particular, the Mann-Whitney $U$ test was used to identify differences between the urban and rural samples (IBM 2019). In cases where a statistically significant difference featured $(p<0.05)$, effect sizes were calculated where $r=-0.1$ indicates a weak, $r=-0.3$ notes a medium, and $r=-0.5$ points to a large effect size. The study adhered to the ethical standards associated with social science research and was approved by the Ethics Committee of the Faculty of Humanities, University of Pretoria. Respondents were required to give consent to participate prior to the interviews by signing a consent form which informed them about the purpose of the study, voluntary participation, and that they could withdraw from the interview at any time. Due to the nature of the research, and the fact that the researcher had to interview homeless individuals in public places, potential risks to the researcher were assessed during the planning phase of the study, and measures were taken to minimise such risks. To ensure anonymity, none of the respondents' names or any information that could be traced back to them were recorded. After the completion of each survey, participants were asked whether they needed to see a counsellor because of the sensitive nature of some of the questions asked. However, no one requested such services. 


\section{Results and discussion}

\subsection{Background characteristics}

Homelessness is considered to be gendered, with men more likely to be homeless than women (Makiwane et al 2010, 41). Nearly all respondents ( $\mathrm{n}=67$; 95.7\%) in the survey were male. Evidence shows that the majority of the South African homeless population comprises of adults between the ages of 20 and 50 (Kok et al 2010,31; Makiwane et al. 2010, 41). In the present survey, the average age of respondents was 35 years with an age range of 20 to 60 years. Roughly twothirds ( $n=27 ; 67.5 \%$ ) of urban respondents were 35 years or younger, while $63.3 \%$ $(\mathrm{n}=19)$ of rural respondents were 36 years and older $(p=0.005 ; r=-0.33)$.

Research on homelessness has predominantly focused on the current age of homeless persons without considering the age when they became homeless which is important for determining the causes of homelessness and for implementing policies intended to address homelessness. In the United State of America (USA), research shows a growing number of individuals who are becoming homeless at an older age (Gonyea, Mills-Dick and Bachman 2010, 575576). Conversely, becoming homeless at a young age could lead to prolonged and chronic homelessness (Culhane, Metraux, Bryne, Stino \& Bainbridge 2013, 4; Rothwell, Sussman, Grenier, Mott \& Bourgeois-Guerin 2017, 72; Mayock, Corr \& O'Sullivan 2013, 442). The average age when respondents became homeless was 32 years with a significant difference $(p=0.005 ; r=-0.33)$ between urban (average homeless age 28 years) and rural (average homeless age 37 years) respondents (Figure 1). Urban respondents $(\mathrm{n}=33 ; 82.5 \%)$ were significantly more likely ( $p=0.019 ; r=-0.28$ ) to experience chronic homelessness compared to rural respondents $(\mathrm{n}=7 ; 17.5 \%)$. 
Figure 1: Age when respondents became homeless (\%)

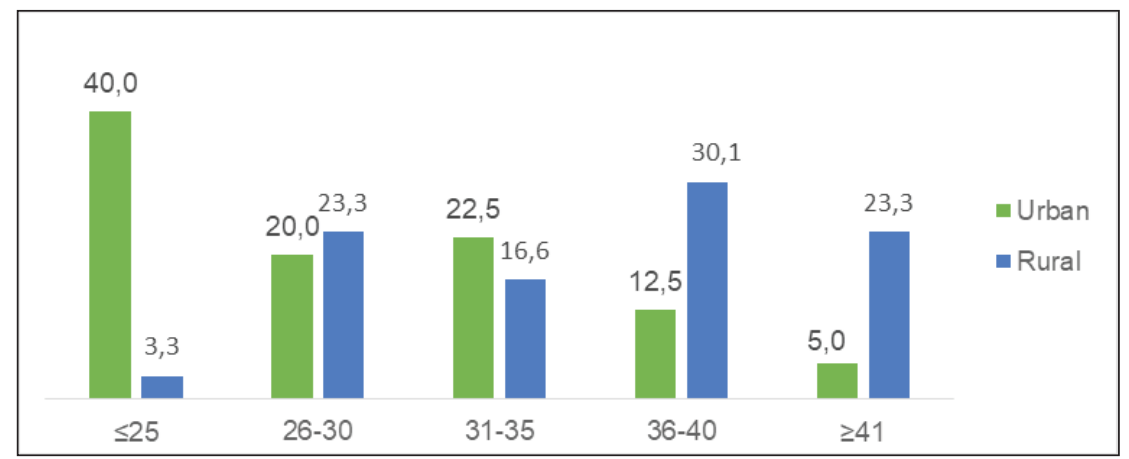

Homeless persons are mainly single individuals who lack ties with society. The survey found that $71.4 \%(n=50)$ of respondents were single. Furthermore, the homeless generally present low levels of education. As a result of being homeless, they forgo educational opportunities, therefore, limiting work experiences (Ferguson, Bender, Thompson, Maccio \& Pollio 2012,387; Makiwane et al 2010, 42). Nearly two-thirds $(\mathrm{n}=45 ; 64.3 \%)$ of respondents achieved Grade 9 or lower, while $27.1 \%(\mathrm{n}=19)$ completed Grade 12 and $8.6 \%(\mathrm{n}=6)$ had a post-school qualification. Education levels showed a significant difference across the two research settings with the urban sample presenting higher levels of education compared to the rural sample ( $p=0.004 ; r=-0.34)$.

Less than two in five respondents $(\mathrm{n}=26 ; 37.1 \%)$ were raised by both parents and one in four $(\mathrm{n}=19 ; 27.1 \%)$ experienced some form of child abuse. Given the high unemployment rate of $30.1 \%$ in South Africa, and $55.2 \%$ among young people between the ages of 15 and 24, the situation does not bode well for the urban homeless (Statistics South Africa 2020). Respondents identified unemployment as the leading cause of homelessness ( $\mathrm{n}=38 ; 51.4 \%)$, followed by being an illegal immigrant $(n=14 ; 18.9 \%)$, breakdown of family life $(n=9$; $12.2 \%)$, having served a prison sentence $(n=7 ; 9.5 \%)$ and substance dependency $(\mathrm{n}=6 ; 8.1 \%)$. Persons who become homeless at a younger age often cite family disorganisation as a reason for being homeless (Collins 2013, 62). The present survey confirms this observation because one in five urban respondents $(n=9$; 19.6\%) cited family breakdown as contributing factor compared to none of the rural homeless. 


\subsection{Homelessness and fear of crime}

Homeless persons report higher levels of fear of crime than the general population which can be attributed to the public nature of their daily lives. Fear of crime is influenced by demographic and neighbourhood characteristics (Baron 2011,477; Kinsella 2012, 128). The survey showed a statistically significant difference $(p<0.001)$ with a large effect size $(r=-0.56)$ between how safe urban and rural respondents feel while living on the street (Figure 2). The difference can be explained by the deviant place theory which suggests that individuals are more likely to fall victim to crime when they are exposed to dangerous places. The theory considers cities as dangerous places since they present higher levels of crime compared to rural areas (Siegel 2010,72).

Figure 2: Respondents' feelings of safety while living on the street (\%)

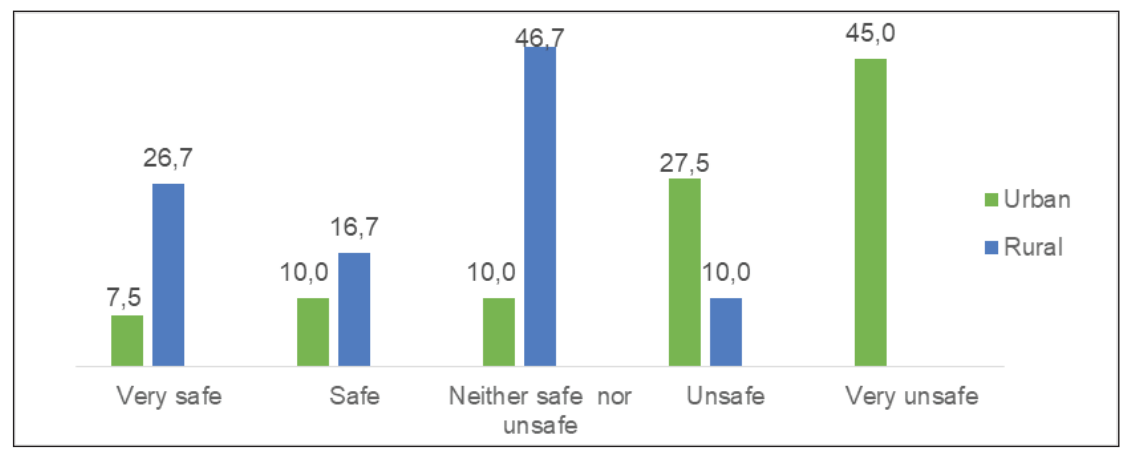

Fear of crime is context-specific and, amongst others, influenced by the environment. Respondents identified twelve spaces where they feel most safe, with the most frequently mentioned safe space being public areas $(n=19 ; 27.1 \%)$. Urban and rural respondents expressed roughly the same level of concern about falling victim to robbery, although significant differences featured in terms of fear of being physically attacked $(p=0.038, r=-0.24)$, theft of goods $(p<0.001 ; r=-$ $0.41)$, and harassment $(p<0.001 ; r=-0.51)$ (Figure 3). 
Figure 3: Respondents' fear of falling victim to types of crime (\%)

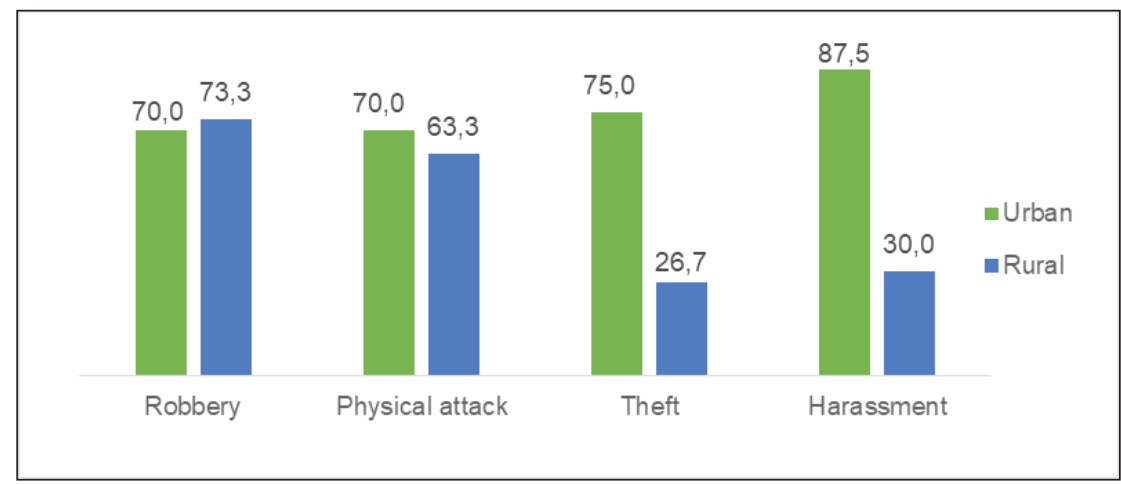

Urban respondents $(\mathrm{n}=32 ; 80.0 \%)$ were significantly more likely $(p<0.001 ; r=-$ 0.54 ) to anticipate falling victim to crime in the future compared to their rural counterparts $(n=8 ; 26.7 \%)$. More than a third of all respondents felt safe in the morning and somewhat less safe in the afternoon (Figure 4). Evenings proved to be the least safe time for both urban and rural respondents. Compared to less than one in ten $(n=3 ; 7.7 \%)$ urban respondents, more than a third of rural respondents $(\mathrm{n}=11 ; 35.7 \%)$ felt safe all day.

Figure 4: Time of day respondents feel most safe (\%)

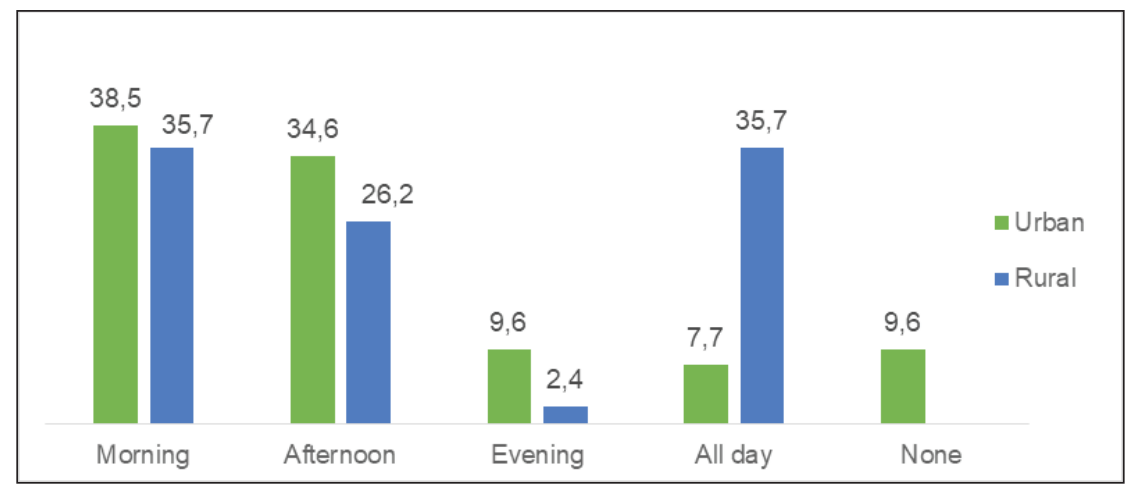

Fear of crime amongst the homeless may be a function of where and with whom they spend their time. The survey showed that the majority of respondents $(\mathrm{n}=57 ; 81.4 \%)$ slept on the street or in public parks $(\mathrm{n}=10 ; 14.3 \%)$, and very few 
made use of the shelters $(n=3 ; 4.3 \%)$. Roughly half of the respondents $(n=36$; $51.4 \%$ ) spent most of their day time in the company of other homeless persons and $61.4 \%(n=43)$ do so at night. The lifestyle exposure theory suggests that the likelihood of victimisation increases when less time is spent with non-family members, especially in the case of younger men who reside in the inner city. While the potential of being victimised by other homeless persons is present, it can conversely be argued that spending time with others, especially at night, might serve as protection against possible threats. In other words, fellow homeless persons could fulfil the role of guardians as the routine activities theory suggests (Tyler, Kort-Butler \& Swendener 2014, 1059; Felson \& Cohen 1980, 392; Tyler \& Beal 2010, 103).

\subsection{Experiences of victimisation}

The prevalence of victimisation amongst homeless persons is evident since they often witness fellow homeless persons being victimised. More than twothirds of respondents $(n=30 ; 42.9 \%)$ knew a homeless person who fell victim to crime. Respondents from the urban setting reported a higher frequency of knowing of a homeless person who fell victim to crime compared to those from the rural sample $(p<0.001 ; r=-0.44)$ (Figure 5).

Figure 5: Responses on how often the homeless fall victim to crime (\%)

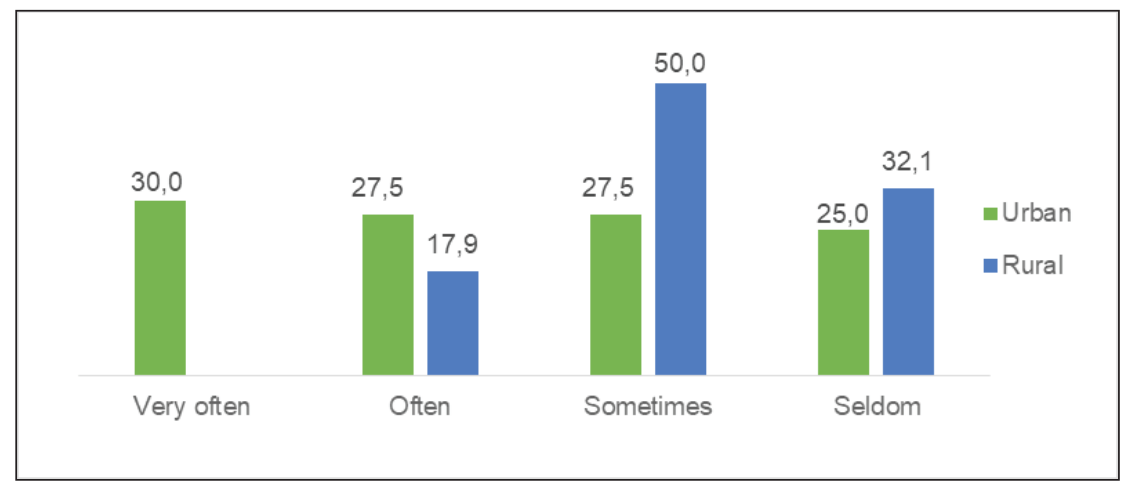


The homeless are more likely to be victimised than the general population. Due to their vulnerability, homeless persons are exposed to violent situations and potential offenders on - daily basis (Dietz and Wright 2005, 38; Scurfield et al 2004, 7). Evidence on the victimisation of homeless people ranges from $32 \%$ to $68 \%$ with the most common form of crimes being physical assault and theft. More than half of the respondents from the present survey ( $\mathrm{n}=37 ; 52.9 \%)$ have been victimised since becoming homeless. Three in five urban respondents $(\mathrm{n}=24 ; 60.0 \%)$ and two in five rural respondents $(\mathrm{n}=13 ; 43.3 \%)$ reported having fallen victim to crime.

Although the survey covered an array of victimisation typologies, only theft and physical assault will be reported here since the n-values of, for example, verbal abuse ( $\mathrm{n}=2 ; 2.9 \%)$, were too low to provide meaningful insights. In the year preceding the survey, 26 respondents $(37.1 \%)$ experienced incidences of theft, which mostly took place on the street. Male offenders perpetrated all cases of theft and they were between 20 and 29 years of age. Fourteen incidences of theft occurred in the evening and twelve during the day. Only six cases of theft were reported to the police. Fifteen respondents $(n=15 ; 21.4 \%)$ were physically assaulted, of which ten incidents took place in the street. The assaults were committed by one female and 17 male perpetrators. In eleven cases the perpetrators were between the ages of 20 and 29 years and they were intoxicated at the time of the assault. Only three of the assaults were reported to the police and in 14 cases respondents suffered physical injury - nine of which sustained serious harm - yet none of them sought medical assistance.

More than half of respondents $(n=39 ; 55.7 \%)$ have used violence to counteract victimisation (Figure 6$)$, and the vast majority of these $(n=35 ; 89.7 \%)$ felt that such behaviour was effective. According to the routine activities theory, predictable activities heightens the possibility of victimisation and it is, therefore, not surprising that nearly one in five urban respondents $(n=7 ; 18.4 \%)$ alter their daily routines (Felson \& Cohen 1980,392). 
Figure 6: Methods respondents used to prevent victimisation (\%)

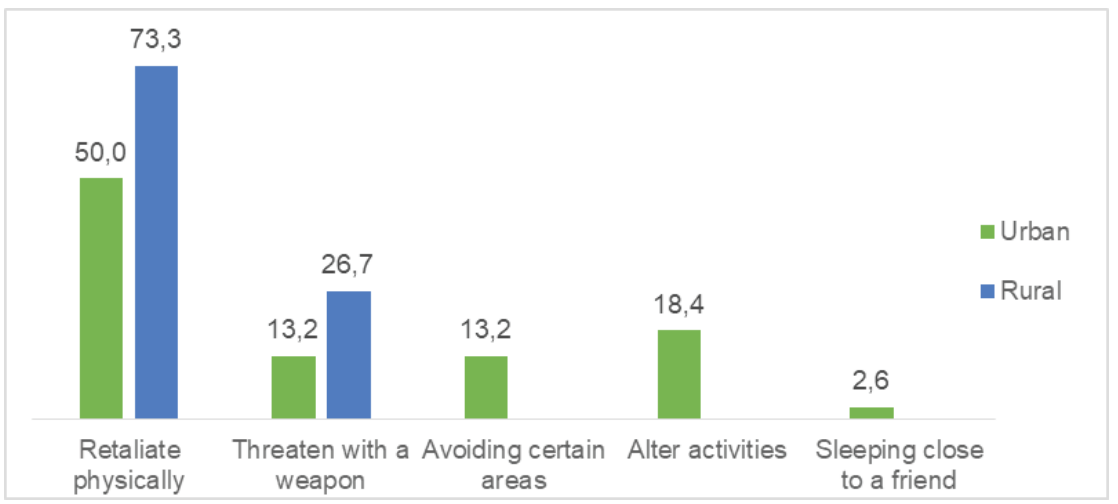

\subsection{The homeless and the police}

Homeless individuals tend to have a negative relationship with the police (McNamara, Crawford \& Burns 2013, 359). When a homeless person commits a serious offence, they must be held accountable, but arrest and imprisonment should be the last resort for homeless persons who commit minor transgressions, especially behaviour that is guided by municipal bylaws (Police Executive Research Forum 2018). It is of concern that the South African metropolitan police, specifically that of Tshwane, Johannesburg, Cape Town, and Ethekwini, barely feature in official policies that affect the homeless. Moreover, an online search for the policies of these four metropolitan police services regarding homelessness yielded no results. In this regard, a survey in the United States showed that $60 \%$ of municipal police and $90 \%$ of sheriff's departments did not have a policy on homelessness (McNamara et al 2013,364-365). It is worthwhile to briefly reflect on the homeless person policies of two police departments in the United States, namely that of Ford Lauderdale (2019) and San Luis Obispo (2019). The two policies broadly state that,

- The homeless have specific needs, including safety and protection, to which police officers must be sensitive.

- Homelessness is not a crime and it cannot be used as justification for detention or unwarranted law enforcement action.

- Procedures are required to guide police officers when engaging with the 
homeless, albeit for casual contact or law enforcement purposes.

- A staff member must be designated as a homeless liaison officer to link with social services and to train fellow officers in legal and social matters related to homelessness.

- The homeless must be offered the same level and quality of service as any other member of society.

- In the case of a homeless person having committed a misdemeanour, referral to support services should be offered in lieu of physical arrest.

- Officers should respect the personal property of homeless persons and should not remove, destroy or discard their property without specific reasons to do so.

In light of their negative relationship with the police, homeless persons are generally unwilling to report incidents of victimisation to the police. As such, it is not surprising that most incidences of theft $(\mathrm{n}=20 ; 76.9 \%)$ and assault $(\mathrm{n}=12$; $80.0 \%$ ) were not reported to the police. Homeless persons' strained relationship with the police extends to their own adverse experiences and interactions with police officers. More than half of respondents $(n=42 ; 60.0 \%)$ stated that they have been harassed by the police, with urban respondents $(n=30 ; 71.4 \%)$ having been significantly more likely than rural $(n=12 ; 40.0 \%)$ counterparts to have experienced such harassment $(p=0.003 ; r=-0.35)$. Rural respondents mostly reported being stopped and searched by police officers, while urban respondents reported a wider variety of forms of police harassment $(p=0.028 ; r=-0.33)$ (Figure 7).

Figure 7: Respondents' encounters with the police (\%)

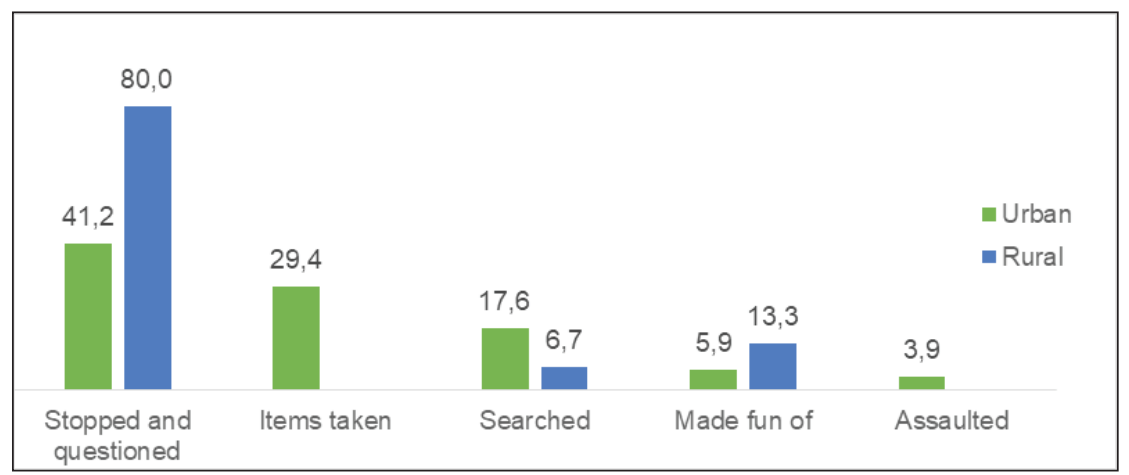




\subsection{Leaving the streets}

The lack of recognition of the street homeless arises as a separate issue in development planning and housing policies. Furthermore, the majority of homeless people are trapped in the cycle of homelessness due to the lack of employment as well as identity documents (South African Institute of International Affairs 2018). The greater proportion ( $\mathrm{n}=67 ; 95.7 \%)$ of survey respondents stated that they would like to leave the streets. Similar to reasons why respondents were homeless in the first place, the bulk of respondents ( $n=26$; $86.5 \%$ ) from the rural setting cited unemployment as an explanation of why they were still homeless (Figure 8). Rates of homelessness frequently correlate with economic conditions and costs of housing and rentals. Pathways out of homelessness often depend on the availability of affordable housing (Hanratty, 2017,640 ). Internationally, various kinds of housing provision have been the most advocated solutions to street homelessness, but it has been almost impossible for the South African government to implement a similar approach given the many uncertainties about the nature and size of the homeless population (Cross et al $2010,144)$. At least $20.5 \%$ of the urban respondents reported a lack of housing as a reason for still being homeless.

Figure 8: Reason still homeless (urban/rural) (\%)

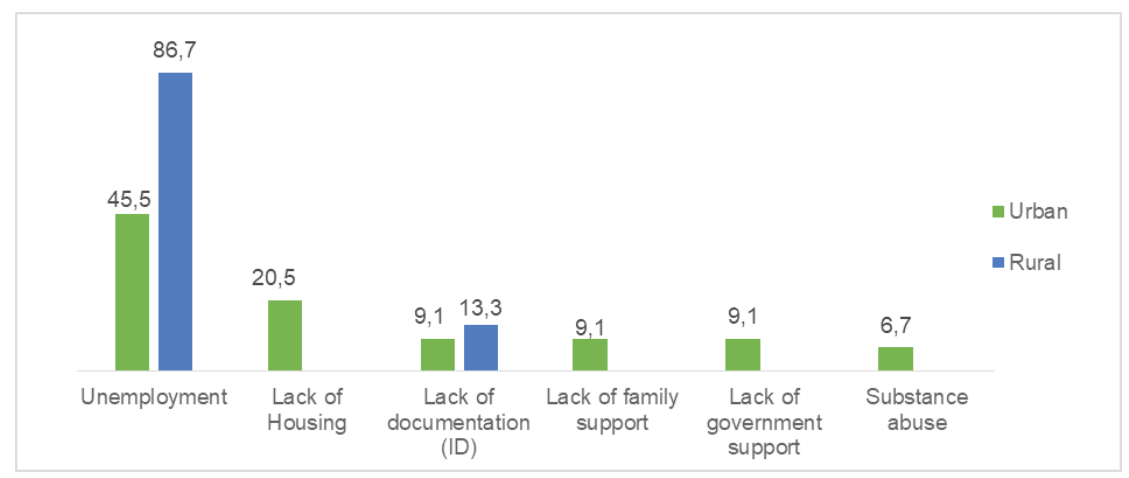




\section{Conclusion}

Living on the street is without a doubt unsafe. The current study sheds light on the vulnerability of the homeless to fall victim to crime, and how troubled personal histories and structural influences shape pathways to homelessness. Homeless people experience the world as an unsafe place. Theirs is a world of exposure to frequent, often never-ending abuse and ridicule, and one in which they are denied respect. The high levels of victimisation and the failure of formal agencies to provide protection are clear indications of the denial of homeless people as victims of crime, and equally so of the denial of the rights generally associated with full citizenship.

With the South African unemployment rate at $30.8 \%$ in the third quarter of 2020 (Statistics South Africa 2020), the background characteristics of homeless persons in South Africa paint a bleak picture for employment prospects, which is exacerbated by low education levels and the age of becoming homeless, particularly amongst the urban homeless who risk becoming chronically homeless. The findings suggest that the rural homeless feel more safe, present lower levels of fear of victimisation, and are less likely to anticipate falling victim to crime in the near future. Similar to the general population, the homeless feel safer in the morning and afternoon which is not surprising since the theft and physical assault appear more likely to take place in the evenings. The profile of perpetrators is similar across settings, i.e. young, intoxicated men who are unknown to the homeless, and it is therefore understandable that homeless victims often retaliate with physical force and weapons to prevent personal harm. The findings further highlight the complex relationships which the homeless have with the police. The homeless needs to be able to seek help when victimised, thus ease of access to criminal justice and health care is essential.

Homeless people's experiences of victimisation need to be recognised on a national and local policy level, therefore, requiring the systematic counting of the homeless population to determine what responses are necessary to assist the homeless. To ensure that the homeless receive the necessary protection from criminal justice system agents, it is important to acknowledge that the homeless can be victims of crime too. Additionally, law enforcement agents should receive training on how to effectively interact with the homeless. Furthermore, alternative strategies- beyond the criminal justice system- should be explored 
as a means of tackling violence and victimisation amongst the homeless. The reliance on criminal justice frameworks yields limited results. Social intervention programmes geared for the homeless should focus on developing and harnessing social support. 


\section{References}

African Union Commission. 2020. No African should be homeless in Africa, practical solutions to forced displacement. Ethiopia, Addis Ababa.

Amore, Kate, Michael Baker, and Philippa Howden-Chapman. 2011."The ETHOS definition and classification of homelessness: An analysis." European Journal of Homelessness 5 (2): 19-37.

Collins, Stephanie Baker. 2013."From homelessness teen to chronically homeless adult: A qualitative study of the impact of childhood events on adult homelessness." Critical Social Work 14 (2): 66- 76.

Baron, Stepehen. 2011. “Street youths' fear of violent crime”. Deviant Behaviour 32 (6): 475-502.

Benyera, Everisto and Chidochashe Nyere. 2015."An exploration of the impact of Zimbabwe's 2005 operation Murambatsvina on women and children. Gender and Behaviour 13 (1): 6522-6534.

Cross, Catherine and John Seager .2010."Towards identifying the causes of South Africa's street homelessness: Some policy recommendations." Development Southern Africa 27 (1): 143-158.

Cross, Catherine, John Seager, Johan Erasmus, Cathy Ward and Michael O'Donovan. 2010. "A review of street homelessness in South Africa and other world regions." Development Southern Africa 27 (1): 269-275.

Culhane, Dennis, Stephen Metraux, Thomas Bryne, Magdi Stino, and Jay Bainbridge. 2013. "The age structure of contemporary homelessness: Evidence and implications for public policy." Analyses of Social Issues and Public Policy 13 (1): 207-232.

de Beer,Stephan and Rehana Vally.2017.“(Finding) pathways out of homelessness: an engaged, transdisciplinary collaborative in the City of Tshwane." Development South Africa 34 (4): 385-398.

Dietz Tracy and James Wright. 2005. "Age and gender differences and predictors of victimisation of the older homelessness." Journal of Elder Abuse and Neglect 17 (1): 37-60.

Dorman, Sara Rich. 2015. "We have not made anybody homeless: Regulation and control of urban life in Zimbabwe." Citizenship Studies 20 (1): 84-98.

Du Toit, Jacques Louis. (2010). "Local metropolitan government responses to homelessness in South Africa." Development Southern Africa 27 (1): 111-128. 
Echenberg, H. and H. Jensen. 2012. Defining and enumerating homelessness in Canada. Ottawa: Library of Parliament.

Felson, Marcus and Lawrence Cohen. 1980."Human ecology and crime: a routine activity approach." Human Ecology 8 (4): 389-406.

Ferguson, Kristin, Kimberly Bender, Sanna Thompson, Elaine Maccio and David Pollio. 2012. "Employment status and income generation among homeless young adults: Results from a five-city, mixed-methods study." Youth \& Society 44 (3): 385-401.

Ford Lauderdale Police. 2019. "Policy 511.0 Homeless persons." https://www.flpd. org/home/showdocument?id=4141.

Garland, Tammy, Tara Richards and Mikaela Cooney. 2010. "Victims hidden in plain sight: The reality of victimisation among the homeless." Criminal Jusrice Studies 23 (4): 285-301.

Gonyea, Judith, Kelly Mills-Dick and Sara Bachman .2010. "The complexities of elder homelessness, a shifting political landscape and emerging community responses." Journal of Gerontological Social Work 53 (7): 575-590.

Hanratty, Maria. 2017. "Do Local Economic Conditions Affect Homelessness? Impact of Area Housing Market Factors, Unemployment, and Poverty on Community Homeless Rates." Housing Policy Debate 27 (4): 640-655

IBM Corp. 2019. IBM SPSS Statistics for Windows. Version 25.0. Armonk, New York: IBM Corp.

Kinsella, Clare. 2012. "Re-locating fear on the streets: Homelessness, victimisation and fear of crime." European Journal of Homelessness 6 (2): 121-136.

Kok, Pieter, Catherine Cross and Niel Roux. 2010. "Towards a demographic profile of the street homeless in South Africa." Development Southern Africa 27 (1): 21-37.

Kriel, lnge, Miriam Julia Paulo Tembe and Victoria Ruvarashe Mashava. 2017. "Homelessness in Pretoria: Exploring the survival challenges of the homeless and their right to the city." Development Southern Africa 34 (4): 428-438.

Kumar, R. 2014. Research methodology: A step-by-step guide for beginners. 4th ed. London: SAGE Publications.

Larney, Sarah, Elizabeth Conroy, Katherine Mills, Lucy Burns and Maree Teesson. 2009. "Factors associated with violent victimisation among homeless adults in Sydney, Australia.” Australian and New Zealand Journal of Public Health 33 (4): 347-351. 
Makiwane, Monde, Tamasane, Tsiliso and Marguerite Schneider. 2010. "Homeless individuals, families and communities: The societal origins of homeless." Development Southern Africa 27 (1): 39-49.

Manganyi, Lukwikilu Credo. 2017. “'Not just numbers!' Homeless people as potential economic contributors in Tshwane." Development Southern Africa 34 (4): 450-467.

Mashau, Thinandavha Derrick .2017. "Unshackling the chains of homelessness in the City of Tshwane: A critical appraisal of the current policy in the light of national and local policies and strategies." Development Southern Africa 34 (4): 414-427.

Mayock, Paula. Mary-Louise Corr and Eoin O'Sullivan. 2013. "Moving on, not out: When young people remain homeless." Journal of Youth Studies16 (4): 441-459.

McNamara, Robert Hartmann, Charles Crawford and Ronald Gregory Burns. 2013. "Policing the homeless: Policy, practice, and perceptions." Policing: An International Journal of Police Strategies and Management 36 (2): 357 - 373

Mitchley, Alex. 2019. "Homeless killings - Fifth body found in Tshwane, police task team deployed." News24. 19 June. https:/www.news24.com/news24/ SouthAfrica/News/breaking-homeless-killings-fifth-body-found-in-tshwanepolice-task-team-deployed-20190619.

Moyo, Unotida, Leila Patel and Eleanor Ross. 2015. "Homelessness and mental illness in Hillbrow, South Africa: A situation analysis." Social Work/Maatskaplike Werk 51 (1): 1- 21.

Naidoo, Vinothan. 2010. "Government responses to street homelessness in South Africa.” Development Southern Africa 27 (1): 129-141.

Newburn, Tim and Paul Rock. 2006. "Urban homelessness, crime and victimisation in England" International Review of Victimology 13: 121-156.

Olufemi, Olusola. 2000. "Feminisation of poverty among the street homeless women in South Africa." Development Southern Africa 17 (2): 221-234.

Police Executive Research Forum. 2018. "The police response to homelessness." Washington, D.C: Police Executive Research Forum. http://www.buttehomelesscoc.com/uploads/1/1/7/5/117500423/ policeresponsetohomelessness.pdf. 
Rattelade Stephanie, Susan Farrell, Tim Aubrey and Fran Klodawsky. 2014. "The relationship between victimisation and mental health functioning in homeless youth and adults." Journal of interpersonal violence 29 (9): 1606-1622.

Roets, Leon,Annali Botha, Minrie Greef, Sarie Human, Herman Strydom, Martha Watson and Shingairai Chigeza. 2016. "A synthesis of homelessness in South Africa: A rapid critical appraisal.” Development of Southern Africa 33 (5): 613627.

Rothwell, David, Tamara Sussman, Amanda Grenier, Sebastian Mott and Valerie Bourgeois-Guerin. 2017. "Patterns of shelter use among men new to homelessness in later life: Duration of stay and psychosocial factors related to departure." Journal of Applied Gerontology 36 (1): 71-93.

San Luis Obispo CSU Police Department. 2019. "Policy 464 Homeless persons”. https://afd.calpoly.edu/police/police-administration/policies/400/464homeless-persons.pdf.

Schenck, Rinie, Nicolette Roman, Charlene Erasmus, Derick Blaauw and Jill Ryan. 2017. "Homeless in observatory, Cape Town through the lens of MaxNeef's fundamental human needs taxonomy.' Social Workl 53 (1): 266-287.

Schiff, Jeannette Waegemakers, Rebecca Schiff, Alina Turner and Karine Bernard. 2015. "Rural homelessness in Canada: Directions for planning and research." Journal of Rural and Community Development 10 (4): 85-106.

Scurfield, Jessie, Phil Rees and Paul Norman. 2004. "Criminal victimisation of the homeless: An investigation of big issue vendors in Leeds." Radical statistics, 99: 3-11.

Siegel, L. 2010. Criminology: The core. 4th ed. Belmont, CA: Thomson/Wadsworth. Skott-Myhre, Hans, Rebecca Raby and Jamie Nikolaou. 2008. "Towards a delivery system of services for rural homeless youth: A literature review and case study.” Child and Youth Care Forum 37 (2): 87-102.

Somerville, Peter. 2013. "Understanding homelessness." Housing, Theory and Society 30 (4): 384-415.

Statistics South Africa. 2020.Unemployment rate 2019/2020.Pretoria: Government Printers.

Tipple, Graham and Suzanne Speak. 2005. "Definitions of Homelessness in Developing Countries." Habitat International 29 (2): 337-52. 
Tosi, Antonio. 2010. "Coping with diversity. Reflections on homelessness in research Europen”. In Homelessnes research in Europe, edited by O'Sullivan, Eoin, Volker Busch-Geertsema, Deborah Quilgars and Nicholas Please, 221236. Brussels: FEANTSA.

Tyler, Kimberley, Lisa Kort-Butler and Alexis Swendener. 2014. "The effect of victimization, mental health, and protective factors on crime and illicit drug use among homeless young adults." Violence and Victims 29 (2): 348-362.

Tyler, Kimberly and Morgan Beal. 2010. "The high-risk environment of homeless young adults: consequences for physical and sexual victimization." University of Nebraska: Sociology Department, Faculty Publications.

United Nations Centre for Human Settlements. 2000. Strategies to combat homelessness. Nairobi: HABITAT Report. 